has been shown unequivocally in the treatment of bleeding peptic ulcer.'

One of the important reasons given for lack of efficacy of conventional medical regimens in the control of bleeding from peptic ulcer is their inability to adequately control intragastric acidity by failing to maintain sustained intragastric achlorhydria, ${ }^{9}$ which has been shown experimentally to be essential for stabilisation of clot. ${ }^{4}$ Peterson and Richardson ${ }^{10}$ have shown that sustained achlorhydria can be achieved only with hourly intravenous bolus injections of cimetidine $(100 \mathrm{mg})$ with continuous nasogastric infusion of an antacid at the rate of $0.5 \mathrm{ml} / \mathrm{min}$ and not with conventional doses of $\mathrm{H}_{2}$ receptor antagonists with or without antacids. In a preliminary prospective randomised study in patients with bleeding peptic ulcer using the above regimen we have recently shown that not only could achlorhydria be maintained but also a higher rate of control of bleeding than that obtained with the standard regimen could be achieved." Furthermore, using such a regimen for all subsequent patients with bleeding peptic ulcer we achieved an overall control of bleeding in $75.4 \%$ of patients compared with $56.7 \%$ in the historical controls. ${ }^{12}$

We believe that there is increasing evidence that a relation exists between intragastric acidity, clot formation and peptic ulcer bleeding. ${ }^{11-13}$ Surprisingly, however, there has been no large study of patients with bleeding peptic ulcer treated with an intensive medical regimen ${ }_{1}^{1}$ aimed at complete neutralisation of acid and pepsin with the intent of preventing clot dissolution and rebleeding. Since such a regimen is inexpensive, easily available, and safe, we think there is an impending need for evaluating its efficacy in a large number of patients presenting with bleeding peptic ulcer.

ANIL ARORA R K TANDON All India Institute of Medical Sciences, New Delhi-110029, India

Correspondence to: $\operatorname{Dr} \mathrm{R} K$ Tandon.

1 Peterson WL. Pharmacotherapy of bleeding peptic ulcer. Is it time to give up the search? [Editorial]. Gastroenterology 1989; 97: 796-7.

2 Mann SG, Didcote S, Taylor PH, Hawkey CJ. Prolongation of intragastric bleeding by acid. Prolongation of intragas

3 Patchett SE, Enright H, Afdhal N, O'Connell W, O'Donoghue DP. Clot lysis by gastric juice: an O'Donoghue DP. Clot lysis by gastric
in vitro study. Gut 1989; 30: 1704-7.

4 Green F Jr, Kaplan M, Curtis L, Levine P. Effect of acid and pepsin on blood coagulation and platelet aggregation. A possible contributor to prolonged gastroduodenal hemorrhage. Gastroenterology 1978; 74: 38-43.

5 Collins $R$, Langman $M$. Treatment with histamine $\mathrm{H}_{2}$ receptor antagonists in acute upper gastrointestinal hemorrhage: implications of randomized trials. NEnglf Med 1985; 313: 660-6.

6 Christiansen J, Ottenjann R, Von Ars F and the study group. Placebo controlled trial with
stiansen J, Ottenjann $R$, Von Ars $F$ and the study group. Placebo controlled trial with
somatostatin analogue SMS 201-995 in the somatostatin analogue SMS 201-995 in the
bleeding peptic ulcer. Gastroenterology 1989; 97: bleeding

7 Berstad A. Experience with antipepsin agents. Scand $\mathcal{F}$ Gastroenterol 1979; 14 (suppl 55): 121-3.

8 Stael Von Holstein CCS, Eriksson SBS, Kallen R. Tranexamic acid as an aid to reducing blood transfusion requirement in gastric and duodenal bleeding. BMf 1987; 297: 7-10.

9 Reynolds JR, Walt RP, Clark AG, Hardcastle JB, Langman MJS. Intragastric $\mathrm{pH}$ monitoring in acute upper gastrointestinal bleeding and the acute upper gastrointestinal bleeding and the Aliment Pharmacol Therap 1987; 1: 23-30.

10 Peterson WL, Richardson CT. Sustained fasting achlorhydria: a comparison of medical regiachlorhydria: a comparison of medical
mens. Gastroenterology 1985; 88: 666-9.

11 Arora A, Tandon RK, Acharya SK, Tandon BN. The role of sustained achlorhydria in bleeding peptic ulcer. F Clin Gastroenterol 1991; 13: 147-
12 Arora A, Tandon RK, Acharya SK, Tandon BM Treating bleeding peptic ulcer with sustained achlorhydria. Gastroenterol fap 1991; 26: 62-5.

13 Daneshmend TK, Hawkey CJ, Langman MJS Logan RFA, Long RG, Walt RP. Omeprazole vs placebo for acute upper gastrointestinal trial in 1154 patients. Gut 1990; 31: A1206.

\section{But was the procedure really necessary?}

SIR,-Lee and Berhenne report 46 patients rendered stone and fragment free with cholecystolithoptripsy (Gut 1991; 32: 536-8). Seven patients developed recurrent calculi yet six remained asymptomatic. Of the 39 gall stone free patients, 26 were asymptomatic and six complained of persistent abdominal pain similar to that before treatment. Seven other patients rendered pain free still complained of various abdominal symptoms including bloating, cramps, indigestion, nausea, and dyspepsia.

After reading this article, I am suspicious that the symptoms suffered by many of these patients had nothing to do with the gall stones. The fact that some had apparently improved after cholecystolithotripsy does not establish that the procedure should have been done in the first place. Improvement could have been due to the powerful placebo response of the cholecystolithotripsy.

Before evaluating this study we need to know the indications for cholecystolithotripsy. Some of the patients had persistent abdominal pain similar to that before treatment. This raises the important question: Were the symptoms which permitted entry into this trial due to the gal stones? Persistent right upper quadrant abdominal pain commonly occurs in the absence of gall stones and may be due to a functional disorder of the upper gastrointestinal tract. ' Furthermore, several studies have clearly shown that the prevalence of dyspepsia is similar in those who have and do not have gall stones. ${ }^{2-4}$

It seems unlikely that cholecystitis (is there such a thing as chronic cholecystititis?) was an indication for lithotripsy since such patients are quite ill and usually require surgery fairly urgently. Their gall bladders would be unlikely to contract. We are not told that any of the patients were jaundiced or had pancreatitis, so the only remaining indication for removal of the gall stones would be biliary colic. It is possible, of course, that all the patients reported on had typical biliary colic, but this is not stated in the article.

Health ministries, third party payers, and increasingly the public are questioning the introduction of expensive new technology without proper validation. In this study cholecystolithotripsy seems to have taken place on some patients without indications for gall stone removal. Claims for the improvement of symptoms other than biliary colic are not substantiated by a double blind trial and go agains experience. $^{2+}$ If, indeed, there were valid indications for lithotripsy in the patients reported, then the authors should have made these indications explicit in the article. If not, one wonders if the patients would have been better off with no treatment at all.

W G THOMPSON Division of Gastroenterology, Ottawa Civic Hospital, University of Ottawe Ottawa, Ontario, Canada KIY $4 E$

1 Kingham JGC, Dawson AM. Origin of chronic right upper quadrant abdominal pain. Gut 1985; 26: 783-8.

2 Price WH. Gall bladder dyspepsia. BMf 1963; ii: $138-41$.
3 Bainton D, Davies DT, Evans KT, et al. Gallbladder disease; prevalence in a South Wales industrial town. Lancet 1981; i: 1147-9.

4 Barbara L, et al. A population study on the prevalence of gallstone disease. Hepatology 1987; 7: 913-7.

\section{Reply}

SIR, - Dr Thompson wants to know the indications for cholecystolithotripsy and questions if the symptoms in our patients were indeed due to gall stones. Our multidisciplinary team agrees with Dr Thompson that right upper quadrant pain occurs in the absence of gall stones. This is further substantiated by the fact that up to $50 \%$ of patients have persistence of symptoms after cholecystectomy. We gave nine references in our discussion concerning this point. Our results of lithotripsy therefore compare favourably with cholecystectomy.

We are not aware of any institution using gall stone lithotripsy where the protocol does not require the presence of gall stone colic for entry to the study. We would like to assure $\mathrm{Dr}$ Thompson that in our institution in the lithotripsy clinic gastroenterologists and surgeons refer patients for treatment only if gall stone pain is present and if these patients would otherwise have been considered for cholecystectomy. All 220 patients entered into our study were diagnosed as having gall stone pain. We therefore disagree with Dr Thompson that cholecystolithotripsy has taken place in our institution without indication. Our team has decided that patients with so called 'gall bladder dyspepsia' should not be accepted for lithotripsy. One of our previous publications (reference 13 in our article) is more explicit in the acceptance protocol, stating that 'evidence of pain due to the presence of gallstones' is required.

S H LEE H J BURHENNE Department of Radiology, Vancouver General Hospital 855 West 12 th Ave Vancouver BC, Canada V5Z IM9

\section{BOOK REVIEWS}

Gastrointestinal symptoms: clinical interpretation. Edited by J Edward Berk and Walter Haubrich. (Pp 271; illustrated; $£ 28.00$.) Wolfe Medical Publishing, London, 1991.

The modern medical curriculum lays increasing emphasis on 'communication skills.' When I first encountered this jargon, I thought it had something to do with computers, but was reassured to find that it simply means the ability to talk to people. Either as a consequence of this educational initiative, or of the 'holistic' philosophy behind it, medical students seem to be better at history taking. This should be good news for gastroenterology in which, more than in any other branch of internal medicine (if only because the physical signs of disease are so often vague or absent), the aphorism, 'listen to the patient - he will tell you the diagnosis' holds true. But it isn't, because the modern science of gastroenterotechnology attracts the gadget minded and the would be surgeon and repels 
the communicators into family practice. Hence, the increasingly familiar scenario of a patient referred with a detailed and thoughtful letter from a family doctor being subjected in hospital to a mindless sequence of expensive, uncomfortable, and unrevealing investigations.

Here is a book that might reverse the trend. A group of distinguished American physicians have collaborated to produce this volume in which the emphasis is not only on how to take a history, but how to use it to make a diagnosis. Although they are, for the most part, men of mature years, it is clear again and again in the text that they are very much in touch with the diagnostic resources that are now available but they clearly believe that modern technology should be used like a probe rather than a blunderbuss. Not all the chapters are equally successful, and some of the symptoms, such as weight loss and jaundice, are signs rather than symptoms, but always the emphasis is on the history, and a profusion of illustrative cases is used to justify their stance. The opening chapter by Stewart Wolf on 'History taking: the art of dialogue' should be compulsory reading for all of our fraternity, while the two distinguished editors, Walter Haubrich and J Edward Berk, have wise words on the respective topics of 'Abdominal pain' and 'Gaseousness.' And furthermore . . . Do I hear you ask what any of this has to do with keeping up with what's new? Well, think about the patients that you saw last week and this week, and those that you will see next week and the week after, and reflect on how much or otherwise you are helped in your work by reading the absolutely latest edition of 'Current update on the state-of-the-art of everything that's shiny and new in gastroenterology' . . .

I know, I know . . . si la jeunesse savait, si la vieillesse pouvait. This book is long on opinion, but short on data, statistics, and bibliography; people may want to write this stuff, but who has to read it, know what I mean? Yet, in my mind's eye, I see this group of Transatlantic sages as Canute like figures, standing firm against the relentlessly advancing tide of fibreoptic magnetically resonating tomographic ultrasonic sludge. Quixotic perhaps, but one cannot deny they have a certain dignity. Ludicrous as it may be, one is for a moment - only a moment, mind - tempted to join them. Perish the thought and pass me the latest $\mathcal{F}$ Clin Invest.

Nevertheless, read this book. It won't hurt you and you might even learn what you thought that you already knew.

DAVID WINGATE
Fundamentals of gastroenterology with selfassessment workbook. Edited by $\mathrm{L} \mathrm{W}$ Powell and D W Piper. (Pp 276; illustrated; £39.95.) Sydney: McGraw-Hill, 1991.

This excellent primer of gastroenterology was first published in 1975. It now has 12 authors and is in its fifth edition. The 11 chapters are followed by about 10 multiple choice questions for each chapter with answers and references to the relevant text pages.

I need only suggest possible improvements. The line drawings are good and more are needed, perhaps instead of, rather than as well as, the $x$ rays, which rarely reproduce well. More diagrams will help the student to understand difficult mechanisms such as the delivery of 5-aminosalicylic acid to the colon by sulphasalazine and analogues. Symbols and abbreviations could be standardised: $\mathrm{ml}$ and $\mathrm{l}$, not $\mathrm{mL}$ and $\mathrm{L}$; $\mathrm{mmol}$ not $\mathrm{mEq}, \mathrm{mmol} / \mathrm{l}$ not $\mathrm{mg} / 100 \mathrm{ml}$.

Most textbooks would benefit from shortening, by tighter prose, and avoiding tautology (skin rash) and imprecision (measurements, diseases, not parameters, pathologies). Now that there are other contributors the editors may have more and not less work to do in ensuring comprehension without overlap. Thus dyspepsia is discussed, and defined differently, both in Functional Disease (chapter 9, p 210) and in Common Diseases (chapter 11, p 226). Endoscopy and Common Symptoms, the last two chapters, might be better at the beginning of the book or distributed within the relevant organs.

It is impossible to satisfy all readers in distributing space between scientifically interesting and common diseases. Even so it seems curious in 1991 to give the side effects of nonsteroidal anti-inflammatory drugs five lines and Helicobacter pylori seven lines whereas viral hepatitis has 10 pages and hormonal gastrointestinal disease a whole chapter.

Warmly recommended.

J H BARON

All titles reviewed here are available from the BMJ Bookshop, PO Box 295, London WC1H 9TE. Prices include postage in the UK and for members of the British Forces Overseas, but overseas customers should add $£ 2$ per item for postage and packing. Payment can be made by cheque in sterling drawn on a UK bank, or by credit card (Mastercard, Visa, or American Express), stating card number, expiry date, and full name.

\section{NOTES}

\section{Clinical trials}

The British Society of Gastroenterology in conjunction with the British Association for the Study of the Liver are initiating two trials designed to evaluate the use of colchicine and ursodeoxycholic acid in (1) sclerosing cholangitis and (2) primary biliary cirrhosis. All gastroenterologists who would like to enter their patients into either or both of these British trials should contact the respective trial coordinators for further details.

Trial 1-sclerosing cholangitis:

Dr Roger Chapman,

Consultant Gastroenterologist,

John Radcliffe Hospital,

Headington

Oxford OX2 9DU.

Trial 2 - primary biliary cirrhosis:

Dr T Warnes,

Consultant Physician,

Liver Clinic,

Manchester Royal Infirmary,

Oxford Road,

Manchester M13 9WL.

\section{British Medical Laser Association}

A meeting on 'Medical lasers: practice and prospects' will be held on 4-5 December 1991 at the Moat House International Hotel, Glasgow. Further information and registration forms are available from: Dr $\mathrm{N}$ Krasner, Secretary, BMLA, Gastrointestinal Unit, Walton Hospital, Rice Lane, Liverpool L9 1AE.

BSG meeting 25-27 September 1991 withdrawal of presentation

The abstract entitled 'Antineutrophil cycloplasmic autoantibodies directed against cathepsin $G$ in sera from patients with inflammatory bowel disease' by Reumaux D, Colombel JF, Cortot A, et al (Gut 1991; 10: A1218) was withdrawn before the meeting but after $G u t$ had gone to press. 